\title{
Occult Fifth Nerve Dysfunction In Multiple Sclerosis
}

\author{
ANDREW EISEN, DONALD PATY, SHERRILL PURVES and MAUREEN HOIRCH
}

SUMMARY: Somatosensory evoked potentials (SEPs) were recorded following trigeminal nerve stimulation in 25 normal subjects. Mucosal stimulation of the lip resulted in a reduced stimulus artefact. The three initial peaks, N/3, PI9, and N30. measured respectively $12.8 \pm 0.9 S^{-3}, 19.3 \pm$ $1.4 \mathrm{~S}^{3}$, and $28.6 \pm 1.7 \mathrm{~S}^{-3}$. Blink reflex studies were also performed in most of these subjects. In $41.4 \%$ of 29 patients with established or suspected multiple sclerosis. the trigeminal SEP was abnormal. Additional use of the blink reflex raised the

RÉSUMÉ: Nous avons enregistré les potentiels évoqués somato-sensitifs (SEPs) après stimulation du nerf trijumeau chez 25 sujets normaux. La stimulation de la muqueuse des lèvres produisit moins d'arté-facts de stimulation. Les trois pics initiaux, N13, Pl9 et N30, mesuraient respectivement $12.8 \pm 0.9 S^{-3}, 19.3 \pm 1.4 S^{-3}$ et $28.6 \pm 1.7 \mathrm{~S}^{-3}$. Des érudes du réflexe de clignotement furent aussi enregistrées chez la plupart des sujets normaux. Cependant le SEP trigéminal fut anormal chez $41.4 \%$ des 29 patients avec sclérose en plaques certaine ou présumée. Lorsque cette étude était combinée à celle du réflexe de clignotement, l'incidence de malfonction overall incidence of trigeminal nerve dysfunction to $51.7 \%$. None of the patients had clinical evidence of fift $h$ nerve involvement either historically or on examination. Four of seven patients with progressive spinal MS and two patients whose only deficit was that of optic neuritis, had abnormal trigeminal SEPs. It is concluded that occult involvement of the pontine fifth nerve structures occurs frequenty in $M S$ despite the rarity of corresponding clinical findings. The trigeminal SEP is a useful additional neurophysiological method.

du nerf trijumeau devint $51.7 \%$. Aucun des patients ne montrait d'évidence clinique (histoire ou examen) d'atteinte du se nerf. De plus, 4 des 7 patients avec sclérose en plaques de forme spinale progressive, et les 2 patients qui ne présentaient qu'une névrite optique, eurent des $S E P$ trigéminaux anormaux. Nous concluons qu'une atteinte occulle du se nerf dans sa portion protubérantielle est fréquente dans la sclérose en plaques même en présence d'une variété de signes cliniques à ce niveau. L'emploi du SEP trigeminal est donc une méthode neurophysiologique utile.

\section{INTRODUCTION}

The value of evoked potentials (EPs) in the diagnosis of multiple sclerosis (MS) is well established (McDonald and Halliday, 1977; Poser, 1980; Chiappa, 1980; McDonald, 1980). These physiological tests, however, add little in patients with definite MS. Their real value lies in detecting subclinical second lesions in patients in whom the diagnosis is suspect.

In this study we describe the value of the trigeminal somatosensory evoked potential in revealing evidence of fifth nerve dysfunction in patients with established or suspected MS in whom facial nerve sensation was normal clinically.

\section{METHODS}

\section{Subjects and patients}

There were 25 control subjects. They either had no medical disease, being recruited from among the medical and paramedical staff of the department, or were patients referred to the laboratory for diseases such as carpal tunnel or cubital tunnel syndromes, considered to be irrelevant in terms of trigeminal evoked SEPs. None gave histories of systemic disease, alcoholism, or treatment with medication likely to affect peripheral or central nervous system conduction. The procedure was carefully explained to the control and patient groups. The mean age of the control group was 42.8 years, with a range of $19-65$ years. Fifteen were female. Twenty-nine patients referred to the laboratory as having established or suspected MS were similarly studied. Their mean age was 41.4 years (range $19-66$ years). Nineteen were female. The patients were classified according to the criteria of McDonald and Halliday (1977) as having definite MS - 6, probable MS (two lesions and 
one episode or two episodes and one lesion) - 8; progressive spinal - 7; and suspected (one typical lesion) -7 . None of the patients had evidence of trigeminal dysfunction either by history or upon clinical examination.

\section{Stimulation and recording}

Electrophysiological testing was performed with the subjects supine. The room was semi-dark and airconditioned, having an ambient temperature of between 20 and $22^{\circ} \mathrm{C}$. Subjects were encouraged to rela $x$ and doze off if they so wished.

The stimulus was a square-wave current pulse of $0.2 \mathrm{~S}^{-3}$ duration applied at a rate of $5 \mathrm{~Hz}$ to each corner of the mouth sequentially. The cathode was so positioned as to be in contact with the mucosal surface of the lip. Stimulus intensity was adjusted to 2.5 times threshold, usually less than $7.5 \mathrm{~mA}$. This was well tolerated. Scalp needle electrodes were used to record the evoked response. One electrode was placed either at $\mathrm{C} 5$ or $\mathrm{C} 6$ (International 10-20 system) contralateral to the side that was stimulated. A referential electrode was positioned at Fpz. A ground electrode was placed around the upper extremity ipsilateral to the side stimulated. Using this recording montage, little difficulty was encountered with the stimulus artefact, which could not be improved upon by placing the ground around the neck or head.

The input from the recording electrodes was led through differential amplifiers having a band pass of $0.5 \mathrm{~Hz}$ $-0.2 \mathrm{kHz}$. The time analyzed was $50 \mathrm{~S}^{-3}$ and 1024 epochs were averaged. After an interval of two or three minutes, a further 1024 epochs were added to the initial averaged response to enhance time-locked events.

Latency measurements were made by use of a cursor on the oscilloscope. Peaks were labelled according to the International nomenclature recommended by Donchin et al (1977). Thus, peaks having latencies of $20 \mathrm{~S}^{-3}$ or less were labelled to the nearest millisecond, whilst those with mean values greater than $20 \mathrm{~S}^{-3}$ were labelled to the nearest $5 \mathrm{~S}^{-3}$. A component was also identified by its polarity. $\mathrm{N}=$ negative, $\mathrm{P}=$ positive, and using the cephalic referential system described above, surface negativity was upward deflecting.

Primary and secondary components of the blink reflex (Kugelberg, 1952; Kimura et al, 1970; Shahani and Young, 1972) were recorded from the orbicularis oculi muscles bilaterally. A small scalp needle electrode was used to record the responses against a reference electrode positioned at Fpz, as used when recording the SEPs. Stimuli were delivered at a rate of not more than once every two seconds to the supraorbital notch. Stimulus intensity was adjusted so that the largest responses were obtained with the least discomfort. Five trials were superimposed and responses having the shortest latencies were measured.

In this study, latencies of the various peaks of the SEP and blink reflex components were considered abnormal if greater than three standard deviations above the normal mean.

\section{RESULTS}

Normal data for the trigeminal SEPs and blink reflex responses are summarized in Tables 1 and 2 respectively. Figures 1 and 2 are representative normal examples of these. Twelve out of the 29 patients (41.4\%) had abnormalities (prolonged latencies or absence) of their trigeminal SEPs. This occurred bilaterally on five occasions. Abnormalities were recorded in 3 of the 6 definite cases of MS, 2 of the 8 probable cases, 4 of the 7 progressive spinal cases, and 3 of the 8 patients with suspected MS. The patients had neither symptoms nor signs indicative of trigeminal nerve involvement. Figure 3 is an example of a patient with progressive spinal MS whose trigeminal SEPs were abnormal bilaterally, whereas a unilateral abnormality is exemplified in Figure 4 recorded from a patient with definite MS.
Eighteen of the 29 patients had blink reflex measurements. Five (27.8\%) demonstrated abnormalities indicative of trigeminal nerve dysfunction. Thus, both ipsi-and contra-lateral secondary responses were absent or difficult to obtain when the involved side was stimulated, but both were of normal latency when the uninvolved side was stimulated (Kimura, 1973, 1975). In addition, the primary component was delayed or absent in these patients. There were abnormalities of the trigeminal SEPs and/or the blink reflex in $15(51.7 \%)$ of the patients.

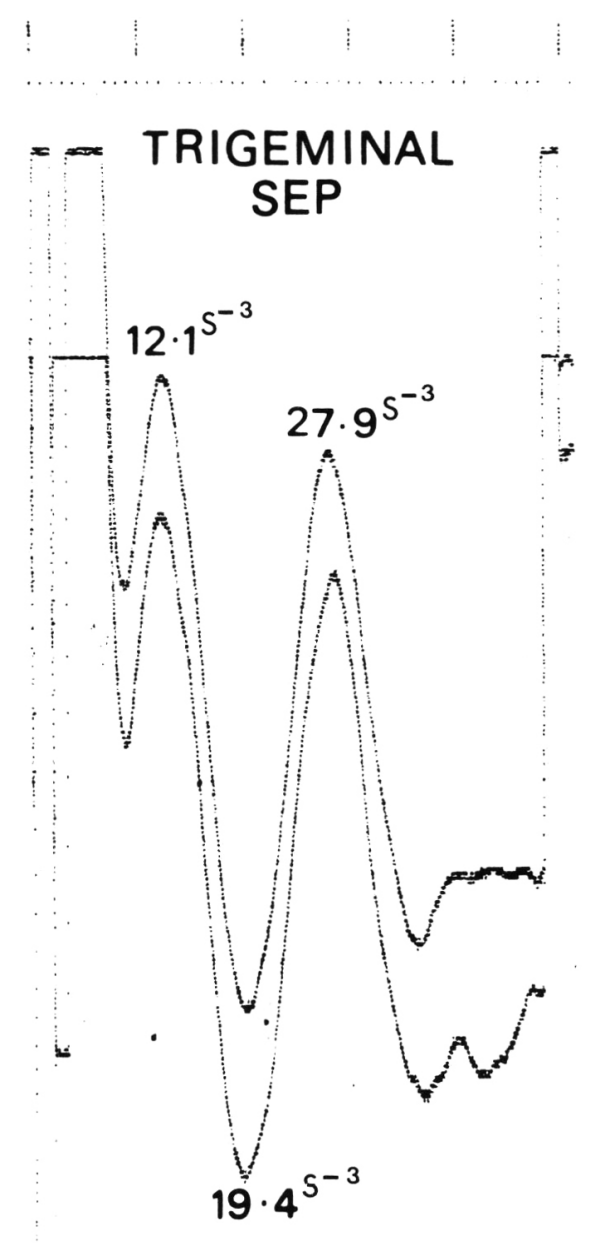

Figure 1-The SEPs shown were recorded following trigeminal nerve stimulation of the left corner of the mouth, the cathode being placed over the mucosal membrane. The top tracing is an average 1024 responses and the bottom trace is the addition of a further 1024 responses. Recordings were made between scalp needle electrodes placed at $\mathrm{C} 6$ and $\mathrm{Fpz}$ (International 10-20 system). 
TABLE 1

Latencies and Side to Side Differences of SEP Peaks Following Trigeminal Nerve Stimulation

\begin{tabular}{|c|c|c|c|c|}
\hline Peak & $\begin{array}{c}\text { Latency }\left(\mathrm{S}^{-3}\right) \\
\overline{\mathbf{x}} \pm \mathrm{SD} \\
\text { (range) } \\
\mathbf{N}=\mathbf{5 0}\end{array}$ & $\begin{array}{l}\text { Upper } \\
\text { Limit } \\
\left(\mathbf{S}^{-3}\right)\end{array}$ & $\begin{array}{c}\text { Side to Side } \\
\text { difference }\left(\mathrm{S}^{-3}\right) \\
x \pm S D \\
\text { (range) } N=25\end{array}$ & $\begin{array}{l}\text { Upper } \\
\text { Limit } \\
\left(\mathrm{S}^{-3}\right)\end{array}$ \\
\hline $\mathrm{N} / 3$ & $\begin{array}{c}12.8 \pm 0.9 \\
(11.6-14.8)\end{array}$ & 15.5 & $\begin{array}{c}0.6 \pm 0.5 \\
(0.1-1.5)\end{array}$ & 2.1 \\
\hline P19 & $\begin{array}{c}19.3 \pm 1.4 \\
(16.6-21.5)\end{array}$ & 23.6 & $\begin{array}{c}0.6 \pm 0.4 \\
(0-1.6)\end{array}$ & 1.9 \\
\hline N30 & $\begin{array}{c}28.6 \pm 1.7 \\
(24.7-32.6)\end{array}$ & 33.6 & $\begin{array}{l}1.2 \pm 0.8 \\
(0-2.9)\end{array}$ & 3.7 \\
\hline
\end{tabular}

TABLE 2

Normal Blink Reflex Studies

\begin{tabular}{|c|c|c|c|c|}
\hline Component & $\begin{array}{c}\text { Latency }\left(\mathrm{S}^{-3}\right) \\
\overline{\mathbf{x}} \pm \mathrm{SD} \\
\text { (range) } \\
\mathbf{N}=\mathbf{4 0} \\
\end{array}$ & $\begin{array}{l}\text { Upper } \\
\text { Limit } \\
\left(S^{-3}\right) \\
\end{array}$ & $\begin{array}{c}\text { Side to Side } \\
\text { difference }\left(S^{-3}\right) \\
x \pm S D \\
\text { (range) } N=20\end{array}$ & $\begin{array}{l}\text { Uppe } \\
\text { Limit } \\
\left(S^{-3}\right)\end{array}$ \\
\hline Primary & $\begin{array}{c}10.0 \pm 0.7 \\
(8.9-11.4)\end{array}$ & 12.1 & $\begin{array}{l}0.4 \pm 0.3 \\
(0=0.9)\end{array}$ & 1.2 \\
\hline $\begin{array}{l}\text { Ipsilateral } \\
\text { Secondary }\end{array}$ & $\begin{array}{c}33.6 \pm 2.1 \\
(29.4=36.1)\end{array}$ & 39.8 & $\begin{array}{c}0.5 \pm 0.4 \\
(0-1.5)\end{array}$ & 1.8 \\
\hline $\begin{array}{l}\text { Contralateral } \\
\text { Secondary }\end{array}$ & $\begin{array}{c}33.9 \pm 2.1 \\
(29.9-37.6)\end{array}$ & 40.4 & $\begin{array}{c}1.2 \pm 0.8 \\
(0.1-2.3)\end{array}$ & 3.5 \\
\hline
\end{tabular}

Difference between ipsilateral and contralateral secondary responses $(N=40)$ measures $0.9 \pm 0.8 \mathrm{~S}^{-3}$. Range $0-2.5 \mathrm{~S}^{-3}$, upper limit $3.3 \mathrm{~S}^{-3}$.

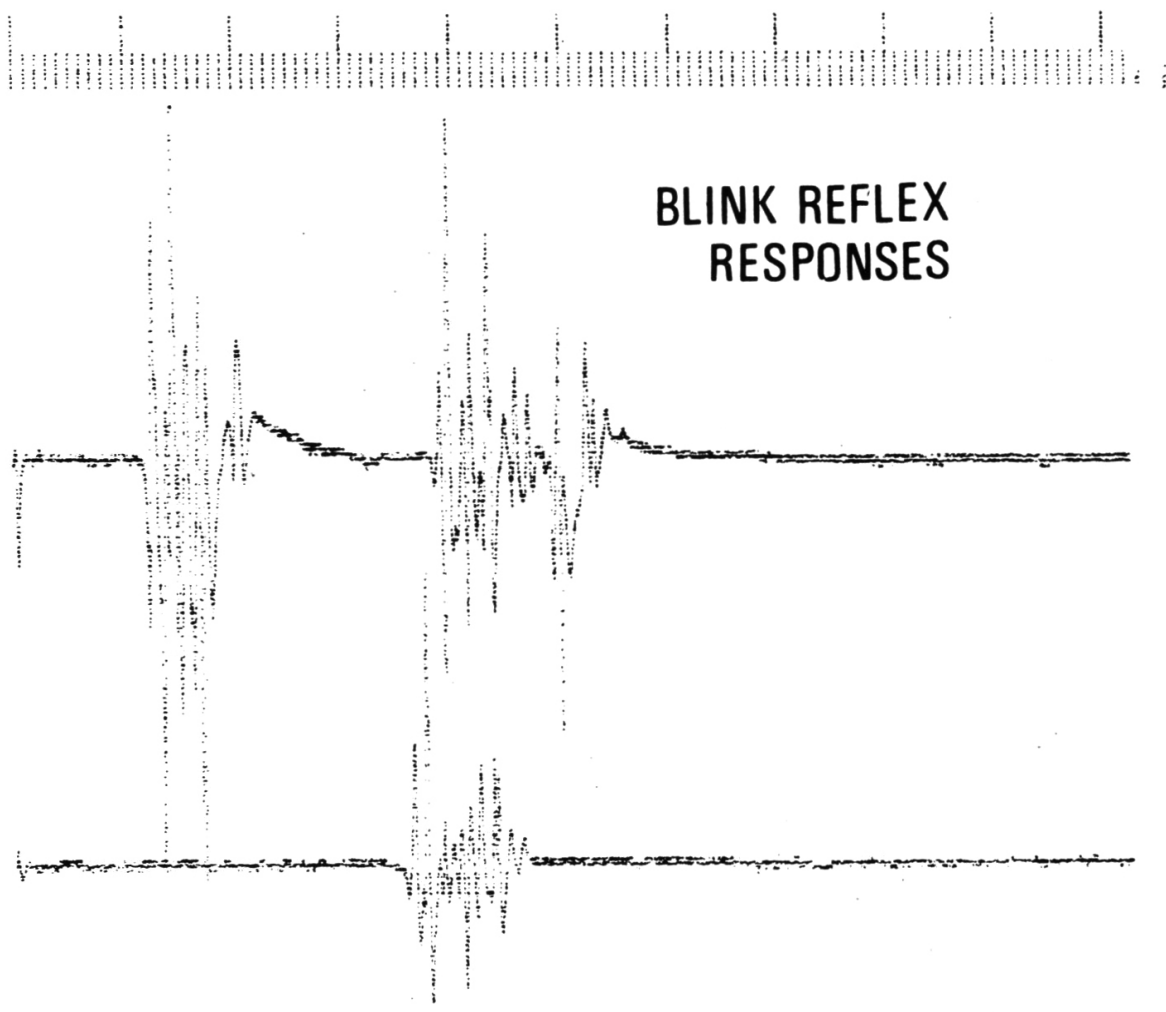

Figure 2-The top tracings represent the primary and ipsilateral secondary responses obtained on stimulating the supraorbital nerve in this normal subject. The bottom trace is the simultaneously recorded contralateral secondary response. Scalp needle electrodes were positioned in the orbicularis oculi with a reference electrode at Fpz.

Either upper or lower extremity cutaneous nerve stimulation was also used to evoke SEPs (Eisen and Elleker, 1980) in all the patients. These were abnormal in 5 out of the 6 definite MS group, all of the 7 patients with progressive spinal MS (using superficial peroneal nerve stimulation), 6 out of the 8 probable group, and 3 of the 8 suspect cases.

\section{DISCUSSION:}

Use of trigeminal nerve stimulation to evoke somatosensory potentials (SEPs) has rarely and only recently been described (Stöhr and Petruch, 1979; Bennett and Jannetta, 1980; Stöhr et al, 1981). Difficulty can arise because of the large stimulus artefact resulting from the proximity of stimulating and recording electrodes.
This problem can be considerably minimized by stimulating mucosal membrane rather than skin, which has a higher impedence (Bennett and Jannetta, 1980). When this is done the first negative peak, N13, is easily recognizable in normal subjects. Accurate positioning of the recording electrode over C5 or C6 (International 10-20 system), which approximately overlie the cortical representation of the face area, is critical because the wave form, especially $\mathrm{N} 13$, is rapidly degraded if the recording electrodes lie much outside these scalp positions. No attempt was made to measure the amplitude of the trigeminal SEPs as, for example, was done by Stöhr et al (1981). In our experience this is too variable in normals to be valuable, although a greater than $50 \%$ side to side difference in amplitude would certainly be relevant. The neural generators of the three peaks of the trigeminal SEP that were measured are not known. Presumably, N13 corresponds to N20 of SEPs recorded following upper extremity stimulation and $\mathrm{P} 40$ recorded with lower extremity stimulation (Eisen and Odusote, 1980), which represent arrival of impulses at the primary somatosensory cortex (Allison et al, 1979).

None of the patients in the present series had clinical evidence of trigeminal nerve dysfunction either by history or on examination. Nevertheless, half of those with definite MS showed abnormalities of their trigeminal SEPs. This incidence of abnormal 


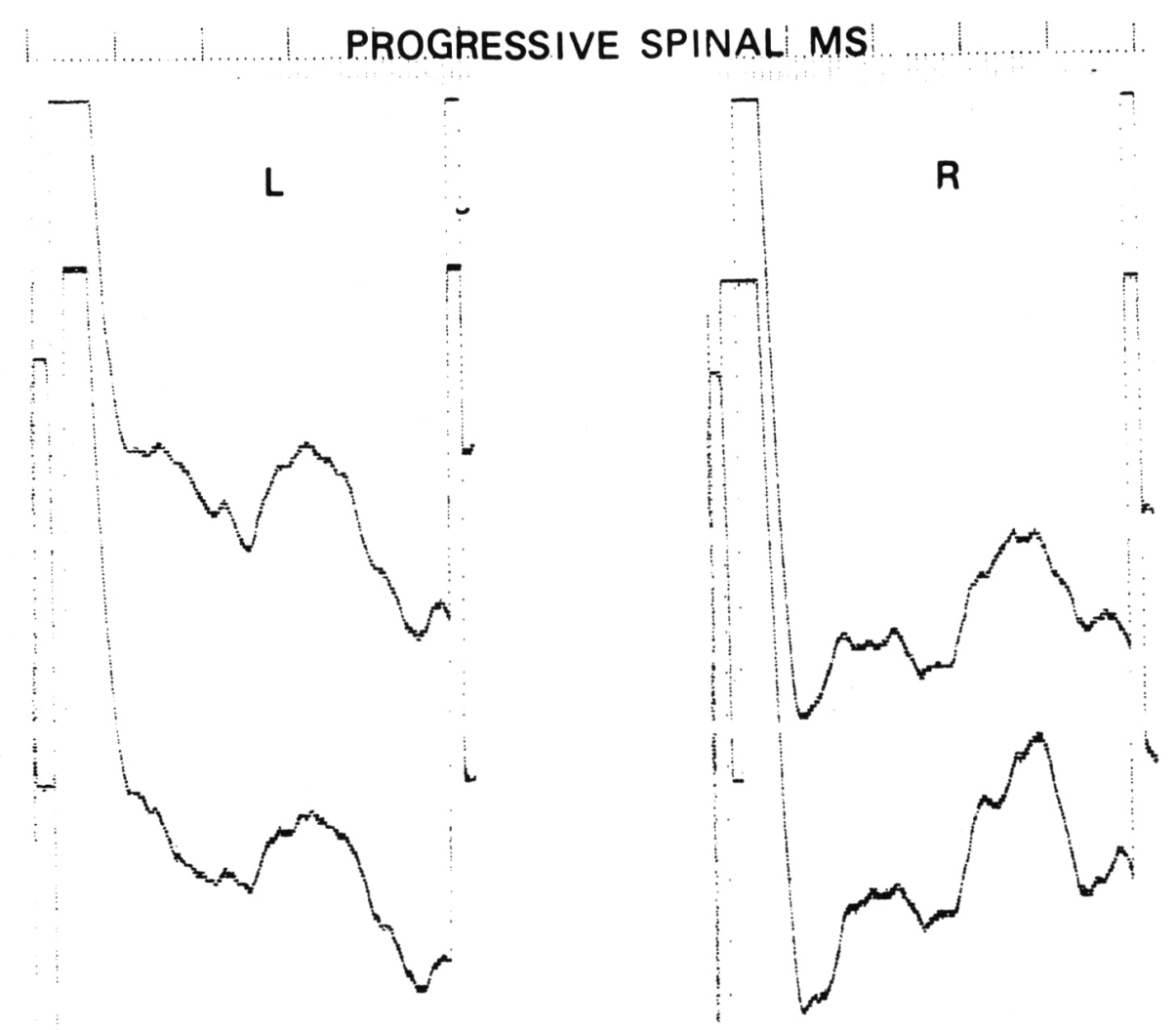

Figure 3-In this patient who had progressive spinal MS, no convincingly recordable trigeminal SEPs could be obtained from either side. The patient had no clinical evidence of abnormal facial sensation.

evoked potentials in patients with clinically definite MS but in whom there were no corresponding clinical findings matches the incidence of abnormal visual evoked potentials (VEPs) in definite MS patients without visual symptoms or signs (McDonald, 1980). However, the incidence of abnormal brainstem auditory potentials (BAEPs) found in definite MS without brainstem involvement is considerably lower (Purves, 1981). The role of VEPs in uncovering occult lesions of the optic nerves in multiple sclerosis is now well established (Poser, 1980). They have been of particular value, for example, in patients with progressive spinal MS. In this subgroup of multiple sclerosis about $40 \%$ of patients have been shown to have abnormalities of VEPs (Halliday et al, 1973; Asselmann et al, 1975; Hennerici et al, 1977; Matthews et al, 1977; Paty et al, 1979). Abnormalities of the VEP in progressive spinal MS clearly indicates involvement outside the spinal cord and confirms the presence of disseminated plaques. All of the patients in this study with progressive spinal MS had abnormalities of SEPs evoked by lower extremity cutaneous nerve stimulation (Eisen and Elleker, 1980). Of much greater interest, however, was the finding that nearly $60 \%$ of this small group had abnormalities of their trigeminal SEP, indicating a lesion rostral to the spinal cord.

Just short of $40 \%$ of our suspects also had abnormal trigeminal SEPs. This in itself is not too helpful, since it mirrors the incidence of abnormal SEPs evoked by more conventional means in MS suspects. More pertinent was the finding that in two of these patients the only clinical abnormality had been one of optic neuritis. This combination of optic neuritis and an abnormal trigeminal SEP would again point to dissemination of lesions.

In a large series of patients, Kimura (1975) demonstrated abnormality of the blink reflex in $78 \%$ of patients with MS who had clinical evidence of

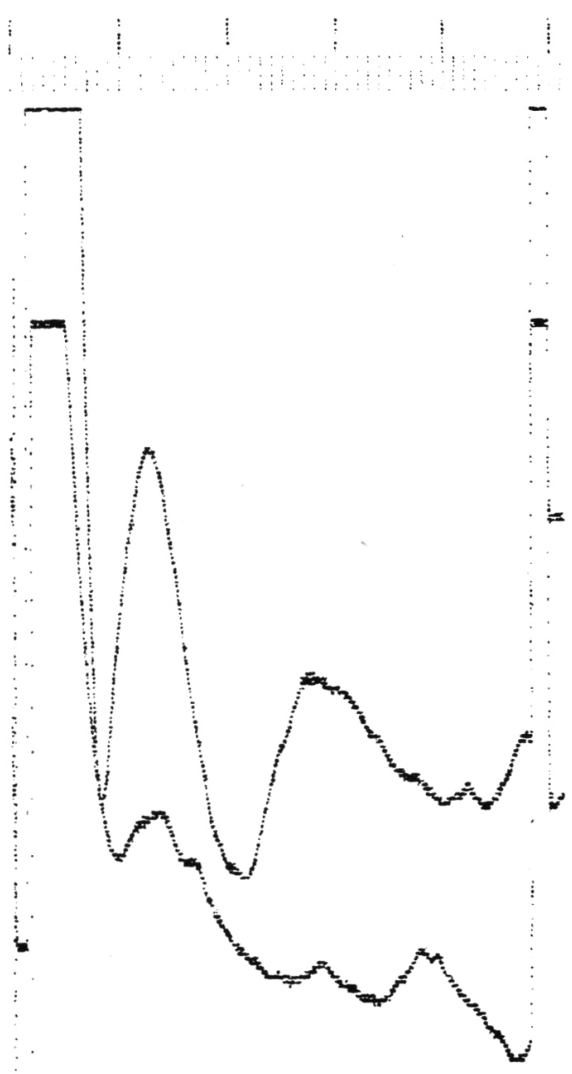

Figure 4-The top tracing of this patient with definite multiple sclerosis was recorded following left sided trigeminal stimulation. It is a normal response. The bottom tracing was recorded following stimulation of the contralateral side of the mouth and no measurable SEP was obtained.

pontine involvement. This incidence of abnormality dropped to $40 \%$ when there were no such clinical features. In the present much smaller series, just short of $30 \%$ of the patients had abnormalities of their blink reflexes, which were specifically indicative of trigeminal nerve involvement. These were all clinically asymptomatic. Using the trigeminal SEP and blink reflex in combination, occult involvement of trigeminal pathways was documented in half the patients. This is a slightly higher yield than obtained with VEPs in patients with possible or probable MS who had no history of optic neuritis (Chiappa, 1980). Although transitory perioral numbness 
and tingling are not uncommon in multiple sclerosis, isolated objective facial sensory deficit is rare apart from trigeminal neuralgia (McAlpine et al, 1965; Poser et al, 1980). This discrepancy between the apparent frequency of occult lesions and clinical findings should not cause concern. It is well known that the extent of lesions in multiple sclerosis is frequently greater than would be anticipated from clinical observations (Ghatak et al, 1974; Wisniewski et al, 1976). In chronic plaques there have been recent suggestions to indicate that relatively normal function can be maintained through the spread of sodium channels into the demyelinated internodal region so that impulse conduction can continue to be supported (Ritchie and Rogart, 1977; Waxman, 1977). Spread of sodium channels in this manner can be considered analogous to the spread of acetylcholine receptors in denervated muscle.

Because the trigeminal SEP appears to be useful in revealing occult brainstem plaques relatively frequently, its use could be advantageously combined with that of SEPs evoked by upper and/or lower extremity nerve stimulation. In this way it becomes possible to detect plaques in anatomically different parts of the somesthetic pathways, allowing confirmation of the diagnosis of multiple sclerosis.

\section{ACKNOWLEDGEMENT}

Supported by the Multiple Sclerosis Society of Canada

\section{REFERENCES}

ALLISON, T., GOFF, W.R., WILLIAMSON, P.D., and VAN GILDER, J.C. (1979). On the neural origin of early components of the human somatosensory evoked response. In: Progress in Clinical Neurophysiology, vol. 7. pp. 51-68, edited by J.E. Desmedt. Karger: Basel.

ASSELMAN, P.. CHADWICK, D.W. MARSDEN, C.D. (1975). Visual evoked responses in the diagnosis and management of patients suspected of multiple sclerosis. Brain, 98, 26I-282.
BENNETT, M.H. and JANNETTA, P.J. (1980). Trigeminal evoked potentials in humans. Electroencephalography and Clinical Neurophysiology, 48, 517-526.

CHIAPPA, K.H. (1980). Pattern shift visual, brainstem auditory, and short-latency somatosensory evoked potentials in multiple sclerosis. Neurology, 30(2), 110-123.

DONCHIN, E., CALLAWAY, E., COOPER, R., DESMEDT, J.E., GOFF, W.R., HILLYARD, SA, and SUTTON, S. (1977). Publication criteria for studies of evoked potentials (EP) in man. Report of a committee. In: Progress in Clinical Neurophysiology, vol., 1, edited by J.E. Desmedt. Karger: Basel, pp. 1-11.

EISEN, A. and ELLEKER, G. (1980). Sensory nerve stimulation and evoked cerebral potentials. Neurology, 30, 1097-1105.

EISEN, A., and ODUSOTE, K. (1980). Central and peripheral conduction times in multiple sclerosis. Electroencephalography and Clinical Neurophysiology, 48, 253-265.

GHATAK, N.R., HIRANO, A., LIJTMAER, H., and ZIMMERMAN, H.M. (1974). Asymptomatic demyelinated plaque in the spinal cord. Archives of Neurology, 30, 484486.

HALLIDAY, A.M., McDONALD, W.I., and MUSHIN, J. (1973). Visual evoked potentials in the diagnosis of multiple sclerosis. British Medical Journal, 4, 661664.

HENNERICI, M., WENZEL, D., and FREUND, H.J. (1977). The comparison of small size rectangle and chequer-board stimulation for the evaluation of delayed visual evoked responses in patients suspected of multiple sclerosis. Brain, 100, 119-136.

KIMURA, J. (1970). Alteration of the orbicularis oculi reflex in pontine lesions: study in multiple sclerosis. Archives of Neurology, 22, 156-161.

KIMURA, J. (1973). The blink reflex as a test for brainstem and higher central nervous system function. In: New Developments in Electromyography and Clinical Neurophysiology. vol. 3, pp. 682-691, edited by J.E. Desmedt. Karger: Basel.

KIMURA, J. (1975). Electrically elicited blink reflex in diagnosis of multiple sclerosis review of 260 patients over a seven-year period. Brain, 98, 413-426.

KUGELBERG, E. (1952). Facial reflexes. Brain. 75, 385-396.

MATTHEWS, W.B., SMALL, D.G., SMALL, M. and POUTNEY, E. (1977). Pattern reversal evoked visual potential in the diagnosis of multiple sclerosis. Journal of Neurology, Neurosurgery and Psychiatry, 40: $1009-1114$.
MCALPINE, D., LUMSDEN, C.E., and ACHESON, E.D. (1965). Multiple Sclerosis: A Reappraisal. E. and S. Livingstone, Edinburgh and London.

MCDONALD, W.I. (1980). The role of evoked potential in the diagnosis of multiple sclerosis. In: Progress in Multiple Sclerosis Research, pp. 564-568, edited by Bauer. H.J., Poser, S. and Ritter G. SpringerVerlag, Berlin

MCDONALD, W.I, and HALLIDAY, A.M. (1977). Diagnosis and classification of multiple sclerosis. British Medical Bulletin. 33, 4-8.

PATY, D.W., BLUME, W.T., BROWN, W.F., JAATOUL, N., KERTESZ, A., and MciNNIS, W. (1979). Chronic progressive myelopathy: Investigation with CSF electrophoresis, evoked potentials, and CT scan. Annals of Neurology, 6, 419-424.

POSER, C.M. (1980). Diagnostic techniques in multiple sclerosis. Survey of Ophthalmology 25(2), 91-101.

POSER, S., BAUER, H.J. and EHLERS, C. Th. (1980). Clinicopathological and epidemiological documentation of patients with multiple sclerosis. In: Progress in Multiple Sclerosis Research. pp. 626-628, edited by Bauer, H.J., Poser, S. and Ritter G., Springer-Verlag, Berlin, Heidelberg. New York.

PURVES, S.J.. LOW. M.D., GALLOWAY. J. and REEVES. B. (1981). A comparison of visual, brainstem auditory and somatosensory evoked potentials in multiple sclerosis. The Canadian Journal of Neurological Sciences, vol. 8, No. 1, 15-19.

RITCHIE, J.M. and ROGART, R.B. (1977). The density of sodium channels in mammalian myelinated nerve fibers and the nature of the axonal membrane under the myelin sheath. Proceedings of the National Academy of Science, U.S.A., 74: 211-215.

SHAHANI, B.T., and YOUNG, R.R. (1972). Human orbicularis oculi reflexes. Neurology 22. 149-154.

STÖHR, M., and PETRUCH, F., (1979). Somatosensory evoked potentials following stimulation of the trigeminal nerve in man. Journal of Neurology, 220, 95-98.

STOHR, M., PETRUCH. F.. and SCHEGLMANN, K.. (1981). Somatosensory evoked potentials following trigeminal nerve stimulation in trigeminal neuralgia. Annals of Neurology, 9, 63-66.

WAXMAN, S.G. (1977). Conduction in myelinated, unmyelinated and demyelinated fibers. Archives of Neurology. 34. 585-589.

WISNIEWSKI, H., OPPENHEIMER, D., and MCDONALD. W.1. (1976). Relation between myelination and function in MS and EAE. Journal of Neuropathology and Experimental Neurology, 35, 327. 